\title{
Expression of SOX9 and CDX2 in nongoblet columnar-lined esophagus predicts the detection of Barrett's esophagus during follow-up
}

\author{
Xuefeng Zhang ${ }^{1}$, Maria Westerhoff ${ }^{2}$ and John Hart ${ }^{3}$ \\ ${ }^{1}$ Department of Pathology, Duke University Medical Center, Durham, NC, USA; ${ }^{2}$ Department of Pathology, \\ The University of Washington, Seattle, WA, USA and ${ }^{3}$ Department of Pathology, The University of Chicago \\ Medicine, Chicago, IL, USA
}

\begin{abstract}
The diagnosis of Barrett's esophagus in the United States requires both endoscopically evident columnar-lined esophagus and the presence of goblet cells by histology. Currently, there is no consensus on how patients with nongoblet columnar-lined esophagus should be followed. In this study, we investigated whether biomarkers can be used to predict the detection of goblet cells in follow-up biopsies. Patients with nongoblet columnar-lined esophagus were identified. In 13 of these cases, goblet cells were detected in subsequent follow-up endoscopic biopsies (Barrett's group). Additionally, 26 cases that remained negative for goblet cells in follow-up biopsies served as controls. Immunohistochemistry for CDX2, SOX9, BMP4, SHH, and MUC2 was performed on the initial biopsies and graded independently by at least two pathologists in a masked manner. CDX2 was positive in the nongoblet columnar epithelium of $7 / 13$ cases in the Barrett's group and in $4 / 26$ controls (sensitivity $54 \%$, specificity of $85 \%$, odds ratio (OR) 6.4). Strong and diffuse immunoreactivity for SOX9 was detected in $10 / 13$ cases in the Barrett's group and in 1/26 controls (sensitivity $77 \%$, specificity $96 \%$, OR 83.3). Combining CDX2 and SOX9 as a panel increased sensitivity to $85 \%$, although the specificity decreased to $85 \%$ (OR 30.3 ). SHH, BMP4, and MUC2 expression showed no significant difference between the Barrett's and control groups. In patients with nongoblet columnar-lined esophagus, SOX9 and CDX2 may be useful in identifying a subset of patients who have a higher risk of being diagnosed for Barrett's esophagus (developing goblet cells) and need closer follow-up. Modern Pathology (2015) 28, 654-661; doi:10.1038/modpathol.2014.157; published online 21 November 2014
\end{abstract}

Over the past three decades, the incidence of esophageal adenocarcinoma has risen approximately sixfold in the United States (from 4 to 23 cases per million). ${ }^{1}$ Despite advances in therapy, the 5 -year survival rate for esophageal adenocarcinoma remains less than $15 \% .^{2}$ Early detection and treatment is crucial for the management of esophageal adenocarcinoma, however, the proportion of patients with early-stage disease at diagnosis only slightly increased from $25 \%$ in 1975 to $31 \%$ in $2001 .^{1}$

Barrett's esophagus is the only identified precursor lesion and the most important risk factor for the development of esophageal adenocarcinoma. Patients with Barrett's esophagus have an 11 to

Correspondence: Dr J Hart, The University of Chicago Medicine, 5841 S. Maryland Avenue, MC 6101, Chicago, IL, 60637, USA. E-mail: John.Hart@uchospitals.edu

Received 24 July 2014; revised 23 September 2014; accepted 23 September 2014; published online 21 November 2014
125 fold higher risk for esophageal adenocarcinoma compared with the general population. ${ }^{3-5}$ In the United States, Barrett's esophagus is defined as a change in the distal esophageal epithelium of any length, recognized as columnar-type epithelium on endoscopy, and confirmed to have intestinal metaplasia by biopsy of the tubular esophagus. ${ }^{6}$ Controversy exists on whether intestinal metaplasia with goblet cells should be an essential criterion for the diagnosis of Barrett's esophagus, and there are studies demonstrating a close relationship between esophageal adenocarcinoma and cardiac-type mucosa. ${ }^{7}$ However, multiple studies have shown that columnar epithelium with goblet cells represents the only type of columnar epithelium at significant risk for adenocarcinoma. ${ }^{8,9}$ Thus, the American College of Gastroenterology recommended endoscopic surveillance only for patients with documented intestinal metaplasia of the esophagus. ${ }^{10}$ No recommendation is available to 
Table 1 Demographic and endoscopic information

\begin{tabular}{|c|c|c|c|}
\hline & Barrett's group $(\mathrm{n}=13)$ & Control group $(\mathrm{n}=26)$ & $\mathrm{P}$-value \\
\hline Average age & 54.6 & 50.7 & 0.42 \\
\hline Average number of biopsies on initial endoscopy & 5.3 & 4.1 & 0.09 \\
\hline Average follow-up years & 5.2 & 6.8 & 0.19 \\
\hline Average number of follow-up endoscopy & 1.7 & 1.8 & 0.82 \\
\hline Average number of follow-up biopsies & 11.3 & 8.9 & 0.44 \\
\hline
\end{tabular}

guide the follow-up of patients with nongoblet columnar-lined esophagus. Recently, Westerhoff et $a l^{8}$ reported that among patients with nongoblet columnar mucosa in initial endoscopic esophageal biopsies, $12 \%$ were found to have goblet cells in subsequent biopsies from follow-up endoscopy. Theoretically, that subgroup of patients may be at risk for the development of esophageal adenocarcinoma. Development of a biomarker to identify such a patient population would allow those patients to be enrolled in a surveillance program.

Several cellular signaling pathways responsible for the modulation of intestinal epithelial cell differentiation have been shown to be involved in the development of metaplastic mucosa in Barrett's esophagus, including sonic hedgehog ( $\mathrm{SHH}$ ), bone morphogenic protein 4 (BMP4), MUC2, SRY (sexdetermining region $\mathrm{Y}$ ) box 9 (SOX9), and caudaltype homeobox 2 (CDX2). ${ }^{11-14}$ Increased CDX2, SHH, and BMP4 expression, at both the mRNA and protein levels, have been observed in the nongoblet columnar epithelium of the lower esophagus. ${ }^{15,16}$ However, the clinical and biological significance of these observations remain unclear.

In this study, we investigated whether the expression of these molecules in nongoblet columnar-lined esophagus predicts the detection of goblet cells in follow-up endoscopic biopsies.

\section{Materials and methods}

\section{Case Selection and Clinical Information}

Pathology databases from the University of Chicago and the University of Washington were searched from 1990 to 2008 for esophageal biopsies taken from endoscopically evident columnar-lined esophagus which demonstrated only nongoblet columnar mucosa on histology. At least one follow-up endoscopy was required for study inclusion. A total of 135 cases were reviewed. Of these, 17 cases were found to have intestinal metaplasia with goblet cells (without dysplasia) in follow-up endoscopic biopsies, and were designated as the Barrett's group. Unfortunately, only 13 cases contained adequate tissue left in the blocks for further analysis, and were included in the study. Among the 118 cases that continued to exhibit nongoblet columnar mucosa on follow-up endoscopic biopsies, 26 cases were randomly selected as controls. The demographic and endoscopic information for both groups are
Table 2 Sources and dilutions of primary antibodies used in this study

\begin{tabular}{llccc}
\hline Antibody & Manufacturer & Clone & Dilution & $\begin{array}{c}\text { Incubation } \\
\text { time (min) }\end{array}$ \\
\hline CDX2 & Novocastra & AMT28 & $1: 15$ & 25 \\
SOX9 & R\&D system & AF-3075 & $1: 100$ & 60 \\
MUC2 & Novocastra & CCP58 & $1: 25$ & 60 \\
BMP4 & Novocastra & 3H2 & $1: 10$ & 60 \\
SHH & Abcam & EP1190Y & $1: 200$ & 60 \\
\hline
\end{tabular}

summarized in Table 1. The selected control cases are representative of the 135 patients which are included in this study. There was no statistical difference in the average patient age, initial number of biopsies, number of follow-up procedures, and duration of follow-up between the Barrett's group and the selected control cases (Table 1).

In order to investigate the distribution of CDX2/SOX9positive nongoblet columnar cells in Barrett's mucosa, 11 additional endoscopic mucosal resection (EMR) specimens containing non-dysplastic Barrett's esophagus were selected for further immunohistochemistry (CDX2 and SOX9 only). Immunoreactivity was recorded for columnar mucosa both immediately adjacent to and distant from goblet cells. Distant immunoreactivity is defined as positive columnar cells at least one $40 \times$ high-power field $(0.5 \mathrm{~mm})$ away from the nearest goblet cell. When distant immunoreactivity was present, the maximal distance was measured.

\section{Immunohistochemistry}

Immunohistochemistry was performed on 4-micron-thick paraffin tissue sections. The manufacturers and incubation conditions for primary antibodies are summarized in Table 2. Immunohistochemistry for CDX2 was performed on a Bond-Max automated immunohistochemistry platform (Leica Microsystems Inc., Buffalo Grove, IL, USA) according to the manufacturer's sequential protocol, followed by use of the Bond Polymer Refine HRP detection system (Leica Microsystems Inc.). Immunostaining for SOX9, BMP4, MUC2, and SHH was performed manually. For SOX9, the antigen-antibody reaction was detected using anti-goat-HRP (1:100, R\&D system, HAF 017) and DAB + chromogen system (DAKO, K3468). For $\mathrm{SHH}$, the antigen-antibody reaction was detected with the Envision + system (DAKO, K4003) and DAB + chromogen system. For BMP4, after primary antibody incubation, 
tissue sections were incubated with biotinylated antimouse IgG (1:100, BA-2001, Vector Laboratories), followed by signal detection with the Elite kit (PK-6100, Vector Laboratories) and DAB + chromogen system. For MUC2, the antigen-antibody binding was detected with polymerHRP labeled anti-mouse antibody (DAKO, K4001) and $\mathrm{DAB}+$ chromogen (DAKO, K3468) system.

The immunohistochemically stained slides were evaluated by at least two pathologists independently in a masked manner. A $100 \%$ interobserver agreement was achieved after consensus review of a training set. In keeping with the literature that restricted and weak expression of SOX9 was found in the neck/isthmus of gastric corpus, ${ }^{17}$ focal weak immunoreactivity for SOX9 was present in the columnar epithelium of most cases in this study. Therefore, only strong and diffuse (staining at least all the basal glands in at least a $20 \times$ field) SOX9 immunoreactivity was regarded as positive. For the EMR specimens, immunoreactivity was recorded in the columnar mucosa immediately adjacent to and distant from goblet cells. The maximum distance between positive columnar cells and goblet cells was measured using an eyepiece micrometer.

\section{Statistics}

Student's $t$-test was performed. The sensitivity, specificity, negative, and positive predictive values were calculated using the $2 \times 2$ table. The odds ratio (OR) and confidential interval (CI) was calculated using an internetbased software (http://www.medcalc.org/calc/odds_ ratio.php).

\section{Results}

CDX2 and SOX9 Showed Reasonable Sensitivity and High Specificity for the Detection of Goblet Cells in Follow-Up Biopsies

Nuclear immunoreactivity for CDX2 in the nongoblet columnar epithelium was observed in 7/13 cases in the Barrett's group and in 4/26 controls, resulting in a sensitivity of $54 \%$ and specificity of $85 \%$ (positive predictive value 64\%, negative predictive value $79 \%)$. The $\mathrm{OR}$ is 6.4 (95\% CI 1.4-29.5, $P=0.02$ ) for CDX2. Focal and weak immunoreactivity for SOX9 was seen in most of the cases studied; however, strong and diffuse immunoreactivity for SOX9 was detected in 10/13 cases in the Barrett's group and in 1/26 controls, resulting in a sensitivity of $77 \%$ and specificity of $96 \%$ (positive predictive value $91 \%$, negative predictive value $89 \%$ ). The OR for SOX9 is $83.3(95 \%$ CI $7.7-899.6, P=0.003)$. Eleven cases showed immunoreactivity for at least one of the two markers, including six cases that were positive for both markers, one case that was positive for CDX2 only, and four cases that were positive for SOX9 only. When the two-marker panel was used and positivity was defined as immunoreactivity for at least one marker, the sensitivity increased to $85 \%$, albeit at the expense of specificity (85\%, positive predictive value $73 \%$, negative predictive value 92\%, OR 30.3, 95\% CI 4.8-191.5, $P=0.003)$. The sensitivity, specificity, positive predictive value, negative predictive value, and OR are summarized in Table 3.

\section{SHH, BMP4, and MUC2 Expression did not Show Significant Difference Between the Barrett's and Control Groups}

Immunoreactivity for $\mathrm{SHH}$ were present in all of the cases in both the Barrett's and control groups. Positive immunostaining for BMP4 in stromal cells was observed in $90 \%$ of cases in the Barrett's group and $82 \%$ of the controls. MUC2 was less sensitive compared with CDX2 or SOX9, and was positive in $40 \%$ of the cases in the Barrett's group, as well as in $9 \%$ of the controls. It was worth noting that in the Barrett's group, MUC2 immunoreactivity was seen only in cases that were positive for CDX2 and/or SOX9. Therefore, inclusion of MUC2 in the panel of CDX2 and SOX9 did not increase the predictive value.

\section{CDX2 and SOX9 Immunoreactivity was Present in Columnar Epithelium Both Immediately Adjacent to and Distant from Goblet Cells in Barrett's Mucosa}

In order to further elucidate whether the presence of nongoblet columnar mucosa that exhibits CDX2 or SOX9 positivity might represent a field effect, 11 EMR specimens of nondysplastic Barrett's mucosa with goblet cells were analyzed for these markers

Table 3 Summary of sensitivity, specificity, positive predictive value, negative predictive value, and odds ratio of CDX2 and SOX9 as predictive markers for the detection of goblet cells on follow-up biopsies

\begin{tabular}{|c|c|c|c|}
\hline & $C D X 2$ & SOX 9 & Either \\
\hline Sensitivity (\%) & 54 & 77 & 85 \\
\hline Specificity (\%) & 85 & 96 & 85 \\
\hline Positive predictive value (\%) & 64 & 91 & 73 \\
\hline Negative predictive value (\%) & 79 & 89 & 92 \\
\hline Odds ratio (95\% CI, $P$-value) & $6.4(1.4-29.5,0.02)$ & $83.3(7.7-899.6,0.003)$ & $30.3(4.8-191.5,0.003)$ \\
\hline
\end{tabular}

Abbreviation: CI, confidence interval. 

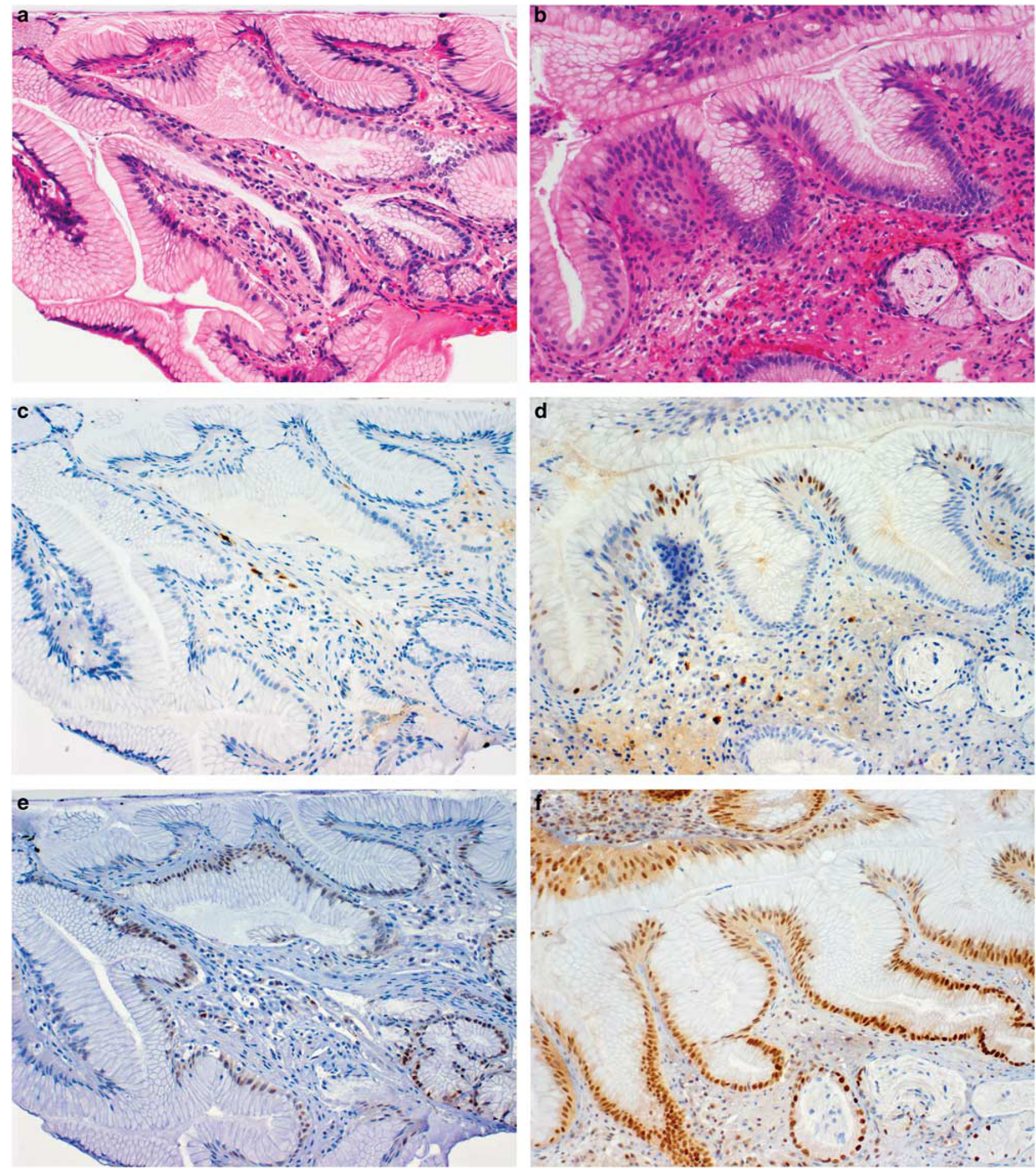

Figure 1 Representative photomicrographs of immunohistochemistry for CDX2 and SOX9 ( $\times 200)$. Left panel (a, c, e): the control group, patients with nongoblet columnar-lined esophagus in initial endoscopic biopsies who remained to be free of goblet cells in follow-up endoscopic biopsies. Right panel (b, d, f): the Barrett's group, patients with nongoblet columnar-lined esophagus in initial endoscopic biopsies who were demonstrated to have goblet cells in follow-up biopsies. a and b, H\&E stain; $\mathbf{c}$ and $\mathbf{d}$, CDX-2; e and $\mathbf{f}$, SOX-9. As focal and/or weak SOX-9 staining is present in most of the cases, only diffuse and strong immunoreactivity for SOX-9 is regarded as positive.

(Figure 1). The results are summarized in Table 4 and representative photomicrographs of the immunostains are shown in Figure 2. Nine of 11 cases showed CDX2 positivity in the columnar mucosa both immediately adjacent to and distant from goblet cells. The average maximal distance of a CDX2-positive nongoblet columnar cell from a goblet cell was $2.7 \mathrm{~mm}$ (range: $0.7-6.0 \mathrm{~mm}$ ). All 11 
cases exhibited SOX9 immunoreactivity in nongoblet columnar mucosa both immediately adjacent to and distant from goblet cells, with an average maximal distance of a SOX9-positive columnar cell to a goblet cell being $4.3 \mathrm{~mm}$ (range $0.7-11.3 \mathrm{~mm}$ ). Although SOX9-positive columnar cells appeared to be present further away from goblet cells than CDX2-positive cells, the average maximal distance of a positive columnar cell to a goblet cell demonstrated no statistical significance between the two markers.

\section{Discussion}

Barrett's esophagus is known to be an acquired process secondary to chronic gastroesophageal reflux disease. Currently, there exists two conflicting hypotheses on the pathogenesis of Barrett's esophagus based on the cell of origin. The first possibility is that Barrett's esophagus arises from stem cells that reside in the stratified squamous epithelium, the submucosal glands of the distal esophagus, the columnar mucosa of proximal stomach, or are

Table 4 The distribution of CDX2/SOX9-positive non-goblet columnar cells in endoscopic mucosal resection specimens for Barrett's esophagus

\begin{tabular}{lrr}
\hline & \multicolumn{1}{c}{ CDX2 } & \multicolumn{1}{c}{ SOX9 } \\
\hline Positive CC immediately adjacent to GC & $9 / 11(82 \%)$ & $11 / 11(100 \%)$ \\
Positive CC distant from GC & $9 / 11(82 \%)$ & $11 / 11(100 \%)$ \\
Average maximal distance of positive CC to GC (range) & $2.7 \mathrm{~mm} \mathrm{(0.7-6.0)}$ & $4.3 \mathrm{~mm}(0.7-11.3)$ \\
\hline
\end{tabular}

Abbreviations: CC, columnar cell; GC, goblet cell.
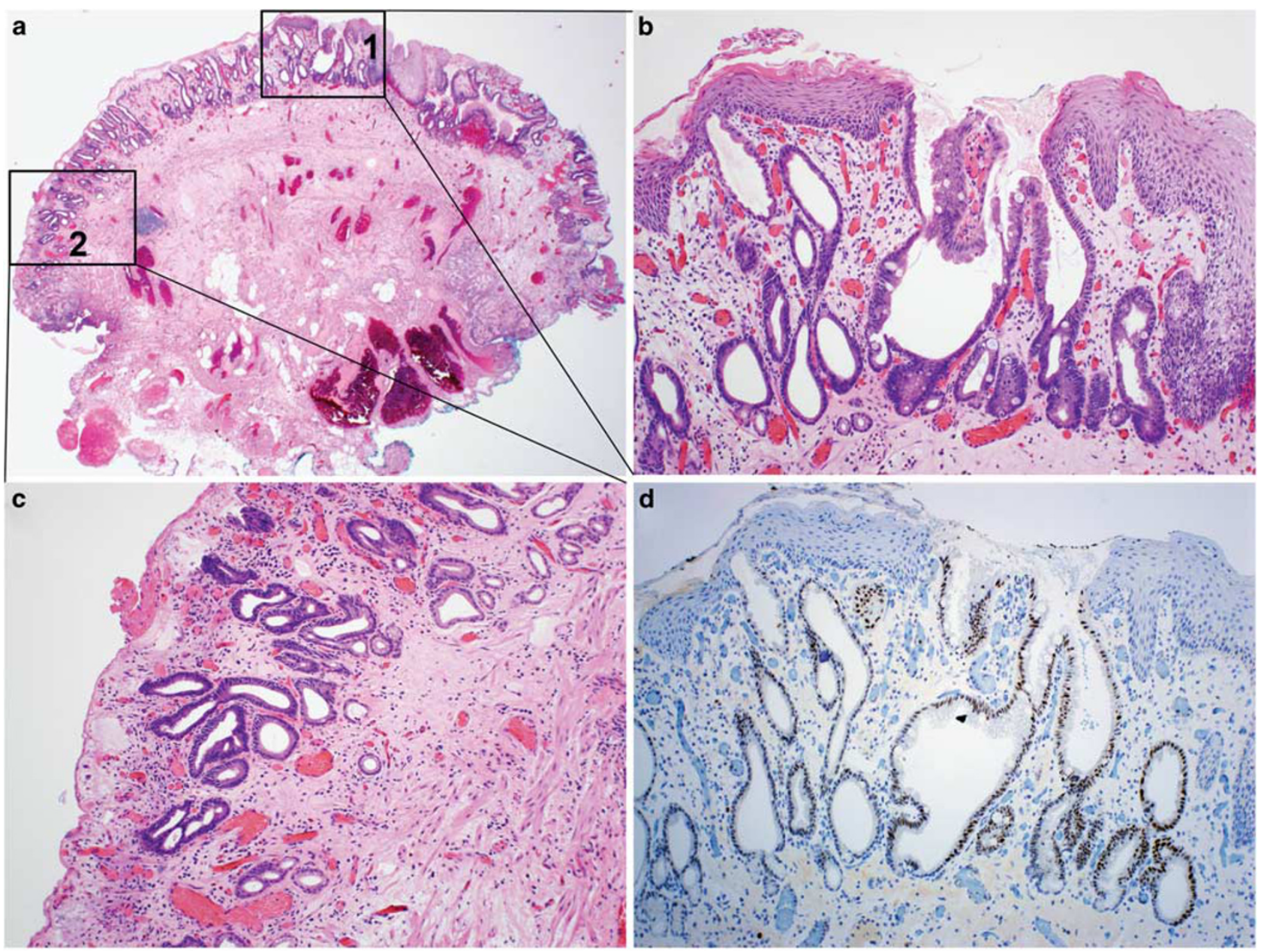

Figure 2 A representative example of the distribution of CDX2- and SOX9-positive nongoblet columnar cells in endoscopic mucosal resection (EMR) specimens from Barrett's esophagus. (a) Low power $(\times 20)$ view of the specimen. (b, d, f) a microscopic focus with goblet cells (box $1,100 \times$ ). Both the goblet cells and nongoblet columnar cells in this focus are positive for CDX-2 (d) and SOX-9 (f). The portion of columnar mucosa to the left of this focus is free of goblet cells. (c, e, g) The focus of nongoblet mucosa the furthest from goblet cells in the specimen (box 2, $100 \times$ ). The nongoblet columnar cells in this focus are positive for CDX-2 (e) and SOX-9 (g). 

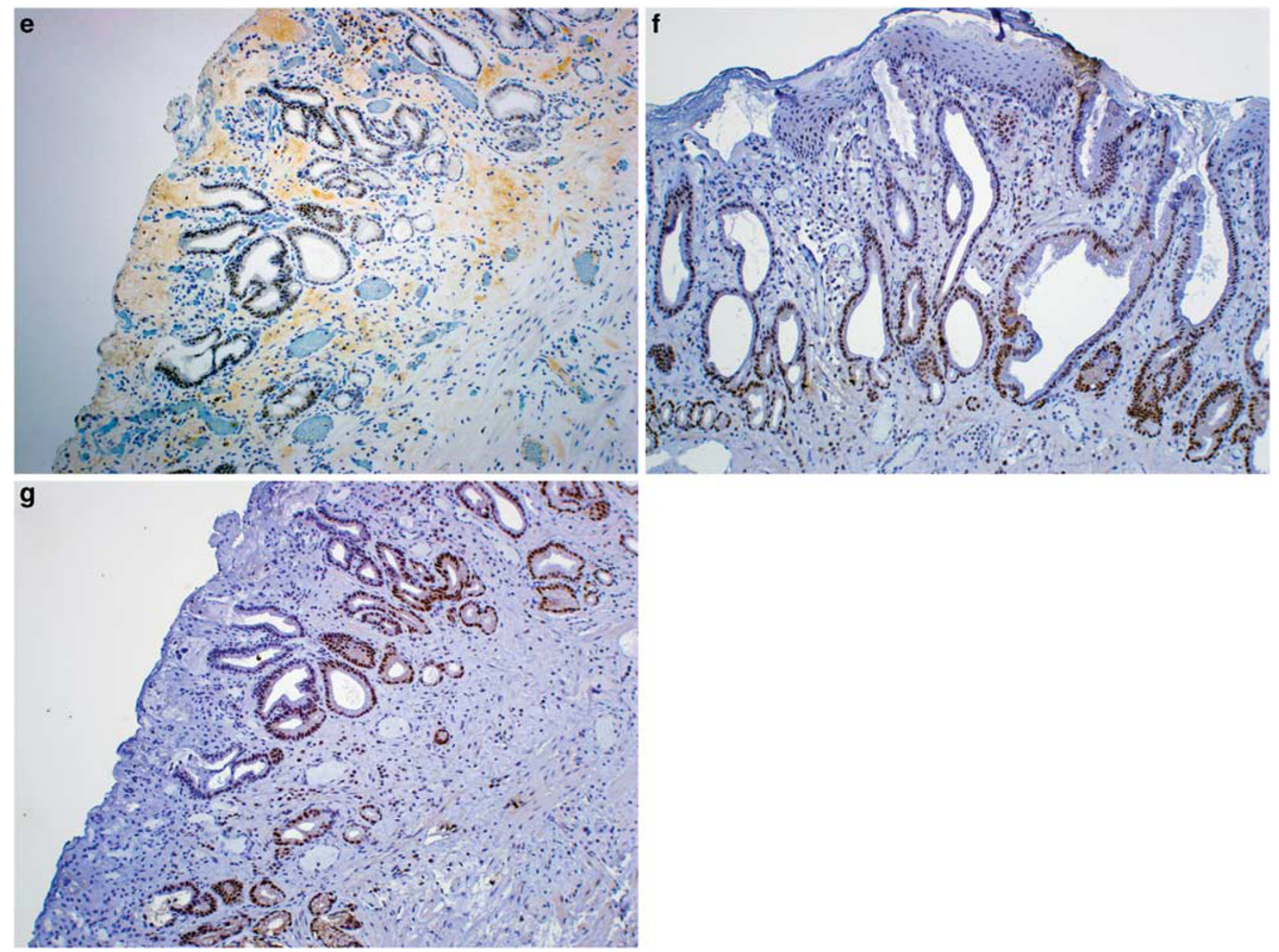

Figure 2 Continued.

bone-marrow-derived. ${ }^{3,12,18}$ The second theory hypothesizes that the cell of origin of Barrett's esophagus is a differentiated esophageal keratinocyte undergoing transdifferentiation. ${ }^{12}$ Regardless of the cell of origin, it is likely that local injurious environmental factors result in an inflamed and damaged squamous esophageal mucosa, and consequently mediate the squamous-intestinal phenotypic switch by altering the expression of a few key tissue-type-regulatory genes, or master switch genes. ${ }^{11}$ Candidate master switch genes, which are upregulated in Barrett's esophagus compared with neighboring normal esophageal squamous epithelium, include CDX1, CDX2, and SOX9. ${ }^{11,12}$

The transcription factor CDX2 seems to play a key role in promoting the cellular biology necessary for an intestinal differentiation, and can be induced by bile salt and acid stimulation. There is conflicting evidence to address whether CDX2 is sufficient to provoke intestinal metaplasia in postnatal esophageal cells. ${ }^{11}$ CDX2 expression is sufficient to induce functional intestinal development in the stomach of transgenic mice. ${ }^{19,20}$ In contrast, the expression of CDX2 in mouse esophageal squamous cells did not initiate a phenotypic switch in an in vivo reconstitution model. ${ }^{21}$ Similar to our studies, CDX2 nuclear immunoreactivity had been observed in nongoblet columnar epithelium adjacent to goblet cells in biopsy specimens. ${ }^{14,22}$ Using EMR specimens, we demonstrated immunoreactivity for CDX2 in nongoblet columnar epithelium both adjacent to and distant from goblet cells. As such immunopositivity was seen at the edge of some specimens, the maximal distance that we identified might actually be underestimated.

The clinical significance of CDX2 expression in nongoblet columnar esophageal mucosa had been studied in a longitudinal retrospective study. ${ }^{14}$ Kerkhof et $a l^{14}$ reported that the detection of CDX2 in cardiac-type mucosa increased the likelihood of finding intestinal metaplasia (goblet cells) in another biopsy from the columnar-lined esophagus in the same patient taken either before or after the biopsy used for the CDX2 stain (OR 3.5, 95\% $\mathrm{CI}=1.2-10, \quad P=0.02)$. This finding argues that CDX2 expression in nongoblet columnar epithelium might represent a field effect, suggesting the co-existence of goblet cells which were not biopsied (this will be discussed in detail later in the discussion). The reported sensitivity $(52.0 \%)$ was similar to that of our study $(53.8 \%)$, but the 
specificity was relatively lower $(76.2 \%$ vs $84.6 \%$ in the current study). A relatively short follow-up period in Kerkhof's report (2.5 years vs 6.7 years in the current study) and different antibodies used for CDX2 immunohistochemistry might explain the discrepancy in specificity.

SOX9 is a transcription factor regulated by the SHH/BMP4 pathway. ${ }^{23}$ The embryonic esophagus expresses $\mathrm{SHH}$ and BMP4 to maintain a columnar phenotype. $^{12}$ Re-establishment of SHH/BMP4 signaling and SOX9 expression in Barrett's esophagus may reset the esophageal epithelium to a time when columnar cells line a primordial esophagus. ${ }^{23}$ Bile acid upregulated the expression of SHH ligands, PATCH1, stromal BMP4, and subsequently SOX9, in the esophageal squamous epithelium. ${ }^{16,23}$ A high $\mathrm{SHH}$ expression level was seen in nongoblet columnar-lined human esophagus compared with squamous line esophagus, but the level significantly decreased in Barrett's mucosa, indicating $\mathrm{SHH}$ might be an important initial factor in the induction and maintenance of a columnar phenotype. ${ }^{16}$ This is consistent with our findings that $\mathrm{SHH}$ and BMP4 were expressed in the nongoblet columnar mucosa of most cases in both the Barrett's and control groups. SOX9 expression has been observed in Barrett's esophagus. ${ }^{23} \mathrm{~A}$ recent study showed that the expression of exogenous SOX9 in squamous epithelial cells induced the formation of columnar-like epithelium with the expression of a columnar differentiation marker, cytokeratin 8, and an intestinal specific glycoprotein, A33, indicating SOX9 may be sufficient to drive columnar differentiation in squamous epithelium. ${ }^{21}$ In keeping with this literature, our findings of SOX9 expression in nongoblet columnar mucosa from patients who were found to have Barrett's esophagus in follow-up biopsies indicate that SOX9 might have an important role in the pathogenesis of Barrett's esophagus. To our knowledge, this is the first report that demonstrates the immunoreactivity of SOX9 in nongoblet columnar mucosa from patients with Barrett's esophagus and characterizes SOX9 as a useful predictive marker for the detection of goblet cells in follow-up biopsies in patients with nongoblet columnar-lined esophagus.

As both CDX2 and SOX9 showed relatively high specificity but suboptimal sensitivity, we combined CDX2 and SOX9 as a panel, and the sensitivity increased to $85 \%$, whereas the specificity slightly reduced to $85 \%$. MUC2 was less sensitive compared with CDX2 or SOX9, and exhibited false-positive staining in control group biopsies. In the Barrett's group, MUC2 immunoreactivity was seen only in cases that were positive for CDX2 and/or SOX9. There was no difference in the expression of BMP4, and SHH between the Barrett's and control groups.

There are two possible interpretations for the expression of CDX2 and SOX9 in patients with nongoblet columnar esophageal mucosa who were subsequently documented to have goblet cells in
Table 5 Detailed biopsy and follow-up information of patients who were diagnosed with Barrett's esophagus on follow-up biopsies (Barrett's group)

\begin{tabular}{lccccc}
\hline Case & CDX2 & SOX9 & $\begin{array}{c}\text { Number } \\
\text { of initial } \\
\text { biopsies }\end{array}$ & $\begin{array}{c}\text { Follow-up } \\
\text { (months) }\end{array}$ & $\begin{array}{c}\text { Number of } \\
\text { diagnostic } \\
\text { biopsies }\end{array}$ \\
\hline 1 & + & + & 1 & 1 & 7 \\
2 & + & + & 4 & 1 & 20 \\
3 & - & + & 4 & 31 & 8 \\
4 & - & + & 4 & 82 & 8 \\
5 & - & + & 4 & 84 & 1 \\
6 & + & + & 4 & 66 & 4 \\
7 & + & + & 5 & 89 & 4 \\
8 & + & - & 5 & 126 & 4 \\
9 & - & + & 9 & 58 & 5 \\
10 & + & + & 9 & 110 & 24 \\
11 & + & + & 10 & 1 & 3 \\
12 & - & - & 8 & 18 & 5 \\
13 & - & - & 2 & 63 & \\
\hline
\end{tabular}

${ }^{\mathrm{a} D i a g n o s t i c ~ b i o p s i e s ~ r e f e r ~ t o ~ t h e ~ f o l l o w-u p ~ b i o p s i e s ~ i n ~ w h i c h ~ g o b l e t ~}$ cells were detected.

follow-up esophageal biopsies. The first possibility is a sampling issue: goblet cells were present in the columnar mucosa when the initial biopsies were taken but were simply not sampled. Our data derived from the EMR specimens support such an interpretation, because CDX2 and SOX9 immunoreactivity was evident in the nongoblet columnar mucosa both adjacent to and distant from goblet cells. In some cases, CDX2/SOX9-positive nongoblet columnar mucosa was present at the edge of the EMR specimen; therefore, we may have underestimated the size of the field effect. It has been reported that the number of biopsies is related to the yield of intestinal metaplasia. One study showed that if eight biopsies were taken from a columnar mucosa-lined esophageal segment, goblet cells were found in $68 \%$ of the patients, compared with a $35 \%$ yield when four biopsies were taken. ${ }^{24}$ In our series, in 8 out of 11 positive (for at least one of the two markers) cases, less than eight biopsies were obtained during the initial endoscopy (see Table 5). Furthermore, in four of these eight cases, a greater number of biopsies were taken in the follow-up procedures that revealed goblet cells, supporting the interpretation of inadequate sampling in the initial procedure. On the other hand, in the other four cases, the number of biopsies taken in the diagnostic follow-up endoscopy was equal to or lower than that in the initial procedure, which indicates that the absence of goblet cells in the initial biopsies may not represent a sampling issue (detailed discussion below). In any event, CDX2 and SOX9 may be of value in predicting the presence of goblet cells in follow-up examinations.

The second interpretation is that the detection of goblet cells in follow-up biopsies reflects the natural progression of disease, and the expression of CDX2 and SOX9 may precede the development of goblet cells in the esophageal columnar mucosa: goblet 
cells were not present when the initial biopsies were obtained, but did appear subsequently. In this scenario, the expression of these markers may actually predict the development of goblet cells in follow-up biopsies. In our series, two of the positive cases were initially presumably adequately biopsied with more than eight biopsies (see Table 5). Goblet cells were detected at 58 and 110 months after the initial biopsy. One patient underwent four additional endoscopic examinations before goblet cells were identified. Inadequate sampling would seem to be a less likely explanation for the initial absence of goblet cells in these two patients, and the subsequent detection of goblet cells in follow-up biopsies might represent true disease progression during the follow-up period.

Regardless of the explanation for the absence of goblet cells in initial biopsies, our results demonstrate that immunoreactivity for CDX2 and/or SOX9 in nongoblet columnar-lined esophagus predicts the subsequent detection of goblet cells in follow-up biopsies. Therefore, in patients with nongoblet columnar-lined esophagus, these markers might be of clinical value in stratifying the risk for Barrett's esophagus (as defined in the United States) and guiding follow-up strategies. Obviously, the strength of our study is limited by the retrospective nature and relatively small sample size. Nevertheless, our results warrant prospective studies to validate the clinical value of CDX2 and SOX9 in the aforementioned clinical scenarios.

\section{Disclosure/conflict of interest}

The authors declare no conflict of interest.

\section{References}

1 Pohl H, Welch HG. The role of overdiagnosis and reclassification in the marked increase of esophageal adenocarcinoma incidence. J Natl Cancer Inst 2005;97:142-146.

2 Eloubeidi MA, Mason AC, Desmond RA, et al. Temporal trends (1973-1997) in survival of patients with esophageal adenocarcinoma in the United States: a glimmer of hope? Am J Gastroenterol 2003;98:1627-1633.

3 Bhardwaj A, McGarrity TJ, Stairs DB, et al. Barrett's Esophagus: Emerging Knowledge and Management Strategies. Patholog Res Int 2012;2012:814146.

4 Hvid-Jensen F, Pedersen L, Drewes AM, et al. Incidence of adenocarcinoma among patients with Barrett's esophagus. N Engl J Med 2011;365:1375-1383.

5 Shaheen NJ, Crosby MA, Bozymski EM, et al. Is there publication bias in the reporting of cancer risk in Barrett's esophagus? Gastroenterology 2000;119: 333-338.

6 Spechler SJ, Sharma P, Souza RF, et al. American Gastroenterological Association technical review on the management of Barrett's esophagus. Gastroenterology 2011;140:e18-e52; quiz e13.

7 Takubo K, Aida J, Naomoto Y, et al. Cardiac rather than intestinal-type background in endoscopic resection specimens of minute Barrett adenocarcinoma. Hum Pathol 2009;40:65-74.

8 Westerhoff M, Hovan L, Lee C, et al. Effects of dropping the requirement for goblet cells from the diagnosis of Barrett's esophagus. Clin Gastroenterol Hepatol 2012;10:1232-1236.

9 Murray L, Watson P, Johnston B, et al. Risk of adenocarcinoma in Barrett's oesophagus: population based study. BMJ 2003;327:534-535.

10 American Gastroenterological Association, Spechler SJ, Sharma $\mathrm{P}$, et al. American Gastroenterological Association medical position statement on the management of Barrett's esophagus. Gastroenterology 2011;140: 1084-1091.

11 Colleypriest BJ, Farrant JM, Slack JM, et al. The role of CDX2 in Barrett's metaplasia. Biochem Soc Trans 2010;38:364-369.

12 Wang DH, Souza RF. Biology of Barrett's esophagus and esophageal adenocarcinoma. Gastrointest Endosc Clin N Am 2011;21:25-38.

13 Badreddine RJ, Wang KK. Barrett esophagus: an update. Nat Rev Gastroenterol Hepatol 2010;7:369-378.

14 Kerkhof M, Bax DA, Moons LM, et al. Does CDX2 expression predict Barrett's metaplasia in oesophageal columnar epithelium without goblet cells? Aliment Pharmacol Ther 2006;24:1613-1621.

15 Castillo D, Puig S, Iglesias M, et al. Activation of the BMP4 pathway and early expression of CDX2 characterize non-specialized columnar metaplasia in a human model of Barrett's esophagus. J Gastrointest Surg 2012;16:227-237; discussion 237.

16 Yamanaka Y, Shiotani A, Fujimura Y, et al. Expression of Sonic hedgehog (SHH) and CDX2 in the columnar epithelium of the lower oesophagus. Dig Liver Dis 2011;43:54-59.

17 Sashikawa Kimura M, Mutoh H, Sugano K. SOX9 is expressed in normal stomach, intestinal metaplasia, and gastric carcinoma in humans. J Gastroenterol 2011;46:1292-1299.

18 Burke ZD, Tosh D. Barrett's metaplasia as a paradigm for understanding the development of cancer. Curr Opin Genet Dev 2012;22:494-499.

19 Mutoh H, Hakamata Y, Sato K, et al. Conversion of gastric mucosa to intestinal metaplasia in Cdx2expressing transgenic mice. Biochem Biophys Res Commun 2002;294:470-479.

20 Silberg DG, Sullivan J, Kang E, et al. CDX2 ectopic expression induces gastric intestinal metaplasia in transgenic mice. Gastroenterology 2002;122:689-696.

21 Clemons NJ, Wang DH, Croagh D, et al. Sox9 drives columnar differentiation of esophageal squamous epithelium: a possible role in the pathogenesis of Barrett's esophagus. Am J Physiol Gastrointest Liver Physiol 2012;303:G1335-G1346.

22 Hahn HP, Blount PL, Ayub K, et al. Intestinal differentiation in metaplastic, nongoblet columnar epithelium in the esophagus. Am J Surg Pathol 2009;33:1006-1015.

23 Wang DH, Clemons NJ, Miyashita T, et al. Aberrant epithelial-mesenchymal Hedgehog signaling characterizes Barrett's metaplasia. Gastroenterology 2010;138:1810-1822.

24 Harrison R, Perry I, Haddadin W, et al. Detection of intestinal metaplasia in Barrett's esophagus: an observational comparator study suggests the need for a minimum of eight biopsies. Am J Gastroenterol 2007; 102:1154-1161. 